ESPAÇO TEMATICO: PROTEÇÃO SOCIAL NO CAPITALISMO CONTEMPORÂNEO:

CONTRARREFORMAS E REGRESSÕES DOS DIREITOS SOCIAIS

\title{
Interesses capitalistas e desafios para a efetivação dos direitos sociais: ataques e regressões
}

\author{
Lais do Nascimento Vidal Lage ${ }^{1}$ \\ https://orcid.org/0000-0002-9622-0969 \\ ${ }^{1}$ Universidade Federal do Rio de Janeiro, Escola de Serviço Social, Programa de Pós-Graduação em Serviço Social, Rio de Janeiro, RJ, \\ Brasil
}

Interesses capitalistas e desafios para a efetivação dos direitos sociais: ataques e regressões

Resumo: Este artigo traz uma reflexão sobre as diversas ofensivas capitalistas nas conquistas civilizatórias alcançadas ao longo da história na sociedade brasileira, com apontamentos sobre o desenvolvimento do capitalismo no mundo e seus rebatimentos no Brasil levando em conta seu contexto sócio-histórico para compreender a formulação e implementação da política social, enquanto uma representação e defesa dos direitos sociais que sofrem a todo tempo, principalmente nos últimos anos a partir do neoliberalismo, regressões e contrarreformas.

Palavras chaves: Política social. Direitos sociais. Capitalismo. Contrarreformas.

Capitalist interests and challenges for the enforcement of social rights: challenges and regressions Abstract: This article presents a reflection on the several offensives of capitalism toward the civilizational achievements of Brazilian society obtained throughout history. The study points out the development of capitalism in the world and its repercussions in Brazil taking into consideration the country's socio-historical context. The article aims to understand the formulation and implementation of social policies, as a representation and defense of social rights, which are constantly subject to setbacks and counter-reforms especially due to the rise of neoliberalism.

Keywords: Social policy. Social rights. Capitalism. Counter-reforms.

Recebido em 31.05.2018. Aprovado em 18.09.2018. Revisado em 28.12.2018.

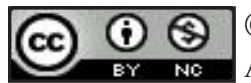

(C) O(s) Autor(es). 2019 Acesso Aberto Esta obra está licenciada sob os termos da Licença Creative Commons Atribuição-NãoComercial 4.0 Internacional (https://creativecommons.org/licenses/by-nc/4.0/deed.pt_BR), que permite copiar, distribuir e reproduzir em qualquer meio, bem como adaptar, transformar e criar a partir deste material, desde que para fins não comerciais e que você forneça o devido crédito aos autores e a fonte, insira um link para a Licença Creative Commons e indique se mudanças foram feitas. 


\section{Introdução}

A promulgação da Constituição Federal em 1988 trouxe inegáveis conquistas legais e civilizatórias na sociedade brasileira, embora a sua efetivação no decorrer da história é demarcada de entraves, lutas e retrocessos que precisam ser analisados, compreendendo a intencionalidade dos atores sociais mediante cada contexto e a posição brasileira em meio ao capitalismo internacional.

Diferentemente do contexto sócio-histórico de muitos países estrangeiros ${ }^{1}$, de origem feudal, no Brasil a revolução se deu pelo alto, sem envolvimento das massas populares e seguiu os interesses da oligarquia nacional a partir de pactos com a burguesia internacional, a fim de manter os interesses econômicos. O novo é perpassado pelo velho, recriam-se formas de trabalho servil, moderniza-se a esfera econômica e se conservam elementos políticos (clientelismo, paternalismo, assistencialismo) possivelmente interessantes aos novos pactos políticos e econômicos, sobretudo, a estrutura social se mantém arcaica, atrasada e com repercussões na atualidade (MAZZEO, 1997).

No processo de constituição do capitalismo brasileiro tivemos a "arcaização do moderno" (FERNANDES, 1976, p. 240), na qual o eixo central consiste em compreender o pacto político tecido entre as elites dominantes que resultaram no desenvolvimento do capitalismo brasileiro. Isso fomentou e acarretou as marcas de uma colocação periférica diante do avanço do capitalismo no mundo (FERNANDES, 1976).

Somado às características da sociedade brasileira de "arcaização do moderno" e "revolução pelo alto" (IANNI, 1981, p. 11), atribui-se ainda outro ponto importante para discussão: a centralidade do Estado em todo esse contexto, afinal, esse se coloca enquanto um Estado que intervém na economia, banca e subsidia os interesses do capital e, portanto, segue a aprofundar as desigualdades sociais e subordinação do capitalismo brasileiro ao capitalismo internacional.

É nessa perspectiva de estudo que pretendo analisar as políticas sociais, compreendendo nelas um viés importante e necessário para efetivação dos direitos sociais conquistados historicamente. Abordarei nesta análise o percurso histórico realizado, principalmente, pelos governos, a fim de atender aos interesses capitalistas e a forma como as conquistas historicamente conquistadas vêm sofrendo ataques e regressões, complexificando frequentemente as relações sociais.

Para construção deste percurso, a metodologia utilizada baseou-se no método materialista histórico dialético para apreender a complexidade da essência dos fatos, fenômenos e acontecimentos ocorridos na realidade concreta.

\section{Contrarreformas e políticas sociais brasileiras no capitalismo contemporâneo: direitos sob ameaça}

O capitalismo contemporâneo e monopolista, não apenas no Brasil, mas em grande parte do mundo, se pauta na obtenção do lucro, exploração do homem pelo homem, com crises cíclicas inerentes a sua constituição e que tem a escassez como uma produção social, afinal, tendo por base a lei geral de acumulação capitalista, o aumento da riqueza socialmente produzida é proporcional ao aumento da pobreza, na qual a produção é social, mas a apropriação é privada (PAULO NETTO, 2011).

É esse capitalismo monopolista contemporâneo, que visando à lucratividade, sua expansão e hegemonia, assumiu, ao longo da história, medidas anticrise implementadas pelas autoridades governamentais para afastar o que poderia ser ameaça à ordem burguesa e como consequência encontrou outros meios para potencializar a disparidade entre ricos e pobres. Nesse âmbito, os avanços capitalistas ocorrem em detrimento da defesa de direitos, principalmente dos direitos sociais.

A mundialização do capital, a perpetuação de sua hegemonia e as medidas anticrises foram assumidas e pensadas de forma ampla e em conjunto por instituições próprias da ordem burguesa, incluindo os intelectuais orgânicos do capital e logicamente o Estado. Nesse cenário, a mundialização se enquadra como mais uma nova face configurada a partir do final do século XX, que tem sua base na esfera econômica, mas que, sobretudo afeta e modela diretamente a vida social em todas as suas extensões e dimensões.

Uma das características do capitalismo, de exploração do homem pelo homem se perpetua: "[...] é na produção que se cria riqueza a partir da combinação social de formas de trabalho humano, de diferentes qualificações" (CHESNAIS, 1996, p. 15, grifo nosso), no entanto, a produção de riqueza nesse contexto mundializado passa a ser comandado pela esfera financeira, mantém-se o "fetichismo da mercadoria", como já anunciava Marx (1988, p. 70) (não apenas fetichismo pela mercadoria produzida a partir do trabalho humano, como também o próprio trabalho como mercadoria), mas adiciona agora a partir das novas necessidades capitalistas o fetichismo da liquidez. 
O estilo de acumulação é dado pelas novas formas de centralização de gigantescos capitais financeiros (os fundos mútuos e fundos de pensão), cuja função é frutificar principalmente o interior da esfera financeira. Seu veículo são os títulos (securities) e sua obsessão, a rentabilidade aliada à "liquidez", da qual Keynes denunciara o caráter "anti-social", isto é, antitético ao investimento de longo prazo. Não é mais um Henry Ford ou um Carnegie, e sim o administrador praticamente anônimo (e que faz questão de permanecer anônimo) de um fundo de pensão com ativos financeiros de várias dezenas de bilhões de dólares, quem personifica o "novo capitalismo" de fins do século XX. (CHESNAIS, 1996, p. 14-15).

Para os países como Brasil, com a inserção periférica e subordinada, não se altera apenas a configuração econômica e política, mas o modo em que o Estado se coloca e adquire novas configurações sendo tocante principalmente no trato com os direitos adquiridos e, sobretudo, com as políticas sociais e com a classe trabalhadora. Para além de defensor dos interesses da burguesia e de braço coercitivo da mesma, o Estado passa agir a partir do "binômio coerção x consenso" (DIAS, 1999, p. 46) em defesa da necessidade de adaptação do País a partir da pretensão do capital financeiro. Não apenas se cruzam as transações e negociações financeiras como também a cultura mundial para homogeneização da população para uma mesma demanda, seja com os bens materiais ou como o modo de pensar e agir, ao cabo que facilita a perpetuação da hegemonia capitalista.

Mediante esse contexto, que compreende a centralidade do Estado para mundialização do capital, os avanços tecnológicos, educação da classe trabalhadora perpassando a ideologia capitalista, suporte às políticas fiscais, privatizações, transferência de responsabilidades estatais ao setor privado, retirada de direitos socialmente conquistados, dentre outros aspectos, não pode obscurecer que toda essa defesa pela lucratividade do capital oferece subsídios para entendermos como a dominação, social e política pela esfera econômica tem rebatimentos diretos e intensos para o agravamento da questão social.

A questão social fomentada a partir da tensão capital x trabalho, compõe nessa nova fase da dimensão capitalista, o leque de duras consequências a ser enfrentadas pelos trabalhadores na dada etapa histórica. E que no caso brasileiro assume características peculiares.

Nesse cenário, a "velha questão social” metamorfoseia-se, assumindo novas roupagens. Ela evidencia hoje a imensa fratura entre o desenvolvimento das forças produtivas do trabalho social e as relações sociais que o impulsionam. Fratura essa que vem se traduzindo na banalização da vida humana, na violência escondida no fetiche do dinheiro e da mistificação do capital ao impregnar todos os espaços e esferas da vida social. (IAMAMOTO, 2011, p. 144)

A forma de enfrentamento da questão social em suas múltiplas refrações torna deficitária a articulação e tomada de consciência dos próprios trabalhadores nesse processo. Afinal, ainda que em tempos de liberalização da economia e desregulamentação dos direitos, as intensas transações bancárias, tributações excessivas e elevadas taxas de juros são funcionais quando produzidas a partir do capital humano. Sem o capital humano como fonte geradora e mantenedora, não há funcionalidade nem efeito o processo de mundialização do capital, nesse sentido, "[...] a esfera estrita das finanças, por si mesma, nada cria. Nutre-se da riqueza criada pelos investimentos produtivos e pela mobilização da força de trabalho, ainda que apareça de forma fetichizada". (IAMAMOTO, 2011, p. 109).

A forma como o capitalismo é remodelado, ao longo da história, redesenha o trabalho - adentra o tecido social, compõe e reconstrói as antigas formas de trabalho -, como: trabalhos domésticos e trabalhos artesanais, além do exponencial crescimento de trabalhos informais. Na contemporaneidade, principalmente na sociedade brasileira, não se vislumbra a possibilidade de romper radicalmente com o arcaísmo das relações passadas, seja pela dependência ao capital internacional, quanto o modo como se desenvolve as relações sociais (políticas subordinadas, baseadas em acordos e relações mediadas por interesses e antigos mandonismos e clientelismos).

Há uma lógica tão perversa que a forma pela qual os trabalhadores encontram para subsistir e atender as suas necessidades básicas os faz enxergar o outro como seu rival. A ideologia dominante da eficiência e do individualismo exacerbado corroem a construção política de consciência de classe. O trabalho humano, ainda que fonte geradora essencial para manutenção do capitalismo encontra-se cada vez mais banalizado. $\mathrm{O}$ aumento da tecnologia, a substituição em grande número de trabalhadores por máquinas, gerou indiferença, banalização, alienação e descartabilidade do trabalho, em potencialização do capital fetiche, que faz da força de trabalho mais uma mercadoria meramente vendável com alto poder de barganha social e pressão por parte da burguesia para bem instituir as condições (precárias) de pactuação trabalhista.

O processo de mundialização e a centralidade do Estado nesse contexto não se limita a esfera econômica, esse processo faz parte e está intrinsecamente relacionado às relações sociais, à defesa dos direitos, lutas políticas etc. que, ao cabo, se complexifica, muda e metamorfoseia o modo como é disseminada a ideologia 
dominante, como se a mundialização fosse alheia às - como diria Behring $(2008$, p. 150) - "contra-reformas" do Estado, reestruturação na esfera produtiva, programática neoliberal e ainda o acirramento da questão social e o trato da mesma pelas autoridades governamentais.

Ao longo da história, o capitalismo vai reformulando as correntes teóricas e políticas que dão base a sua estruturação ao redor do mundo. A partir das suas crises, reformula e reconfigura as nomenclaturas e funções dos organismos próprios do capital para iniciar uma nova etapa na tentativa de êxito para mais alguns anos sob hegemonia capitalista.

Ao citar a crise de 1929, como resultado pro seu enfrentamento, uma série de medidas foram tomadas até que após a $2^{\mathrm{a}}$ Grande Guerra temos a edificação do Welfare State em cenário internacional, também conhecido como Estado de Bem-Estar Social. Nesse âmbito, ocorre uma generalização das políticas sociais, num contexto de alterações substanciais na relação Estado e sociedade civil, sendo colocadas como forma de "[...] amortecer as crises cíclicas de superprodução, superacumulação e subconsumo". (BEHRING; BOSCHETTI, 2011, p. 71 ).

A crise ocorrida em 1929-1932, caracterizada por um período de extrema recessão econômica com consequências, também, para o âmbito social, ocasionou elevadas taxas de desemprego, que se fizeram presente após as quedas na produção industrial, desvalorização das ações no mercado financeiro e quebra na bolsa de valores. A dita crise foi uma demonstração da forma como a busca incessante pela lucratividade, pilar representante do capitalismo, faz girar um ciclo e fomentar as chamadas crises cíclicas (BEHRING; BOSCHETTI, 2011).

A fim de retomar o poderio econômico e reestabelecer a economia do país, os EUA buscou a partir do New Deal ${ }^{2}$ sair da crise que se depararam, junto aos preceitos e ideias advindas do pensador John Maynard Keynes, que emplacou um conjunto de medidas conhecidas mundialmente como Keynesianismo, que defendiam a intervenção e regulação estatal em âmbito econômico. O economista, sobretudo, procurou para a crise capitalista saídas também capitalistas (BEHRING; BOSCHETTI, 2011) e tudo isso resultou na era dos Anos de Ouro, o período que compreendido entre 1945-1975, também conhecido como trinta anos gloriosos.

Buscou-se dessa forma alcançar o pleno emprego e uma maior igualdade social, onde o Estado intervinha na produção e regulação das relações econômicas e sociais, sendo as políticas sociais importante aliada nessa fase do capitalismo.

\begin{abstract}
Nessa perspectiva o bem-estar ainda deve ser buscado individualmente no mercado, mas se aceitam intervenções do Estado em áreas econômicas, para garantir a produção e na área social, [...]. Ao Keynesianismo agregou-se o pacto fordista - da produção em massa para o consumo em massa e dos acordos coletivos com os trabalhadores do setor monopolista em torno dos ganhos de produtividade do trabalho. $\mathrm{O}$ fordismo, então, foi bem mais que uma mudança técnica, com a introdução da linha de montagem e da eletricidade: foi também uma forma de regulação das relações sociais, em políticas determinadas. (BEHRING; BOSCHETTI, 2011, p. 86).
\end{abstract}

Como resposta a essa configuração ocasionada pela crise de 1929 vivenciada principalmente nos países centrais (queda na taxa de lucro e baixo consumo com alto número de desempregados) o Estado passa a alegar e disseminar os ideais preconizados pelo Keynesianismo, a partir dos estudos de Keynes. A defesa era voltada para um Estado interventor nas relações sociais e na economia, ao invés do anteriormente defendido com a intervenção livre do mercado na regulação social, reconfigurando o papel do Estado.

O Keynesianismo teve em seu fundamento: o pleno emprego e ampliação do bem-estar social como resposta a burguesia para crise do capital, que juntamente como o fordismo (consumo em massa para produção em massa), altera a esfera social e o papel do Estado. Houve, portanto, uma generalização das políticas sociais, como instrumento a dar suporte aos trabalhadores em âmbito de saúde, educação e serviços. Garantindo, dessa maneira, trabalhadores aptos ao trabalho, alimentando devidamente a engrenagem do capital, fundamentada na expropriação da mão de obra.

De diferentes formas ocorrera a influência do Estado de Bem-Estar Social em contextos diferenciados. Na particularidade brasileira tivemos de forma focalizada e restrita (ainda que não fosse considerada de fato como Welfare State) ações voltadas para áreas específicas como forma de gerar lucratividade ao capital a partir das políticas sociais. Como foi o caso brasileira da implementação dos Institutos de Aposentadoria e Pensão (IAPs) inicialmente aos marítimos, como uma espécie de previdência. Vale analisar ainda, que houveram ganhos à classe trabalhadora pela generalização das políticas sociais, no entanto, os interesses mascarados por essa ação não podem ser ocultados para não cair na análise unívoca de ações, em ver o Estado como defensor dos trabalhadores e dos direitos sociais. Afinal, a implementação das políticas ocorreu com base em três eixos centrais ao interesse burguês: de controle social, reprodução da força de trabalho e legitimidade da ordem capitalista. 
Adentra os anos 1970, com outro contexto de crise, mas como as mesmas respostas para salvaguardar a hegemonia capitalista: a remodelação do Estado, uma nova configuração para esfera econômica e social, reconfiguração das políticas sociais. Surge então, uma nova ideologia capitalista: o neoliberalismo ${ }^{3}$. Os ideais do neoliberalismo pregavam princípios livres ao mercado e o Estado passa a defender enquanto parceiro, não mais interventor e regulador, movimentando o que defende Neves (2007) enquanto uma: Nova Pedagogia do Capital. As políticas sociais sofrem regressões e são utilizadas como disseminação da ideologia de responsabilidade fiscal, justificando que o quadro vivenciado nesse contexto, de ampliação da desigualdade, corte de gastos, fragmentação acontece porque o Estado não pode arcar com tudo sozinho, sendo necessário a colaboração de todos (empresariado, ONGs, cidadãos), transferindo a responsabilidade para o âmbito social. Metamorfoseando-se de Estado de BemEstar Social para um Estado Parceiro, em que todos devem fazer a sua parte. O Estado passa a incentivar, dessa forma, ações extraeconômicas, repolitiza a política e dá ênfase a esferas políticas - onde iguala a todos, sem corte de classe, "todos são iguais perante a lei" (BRASIL, [2018]) -, fragmenta a classe trabalhadora, na medida que incentiva o voluntariado e dessa forma precariza, desresponsabiliza-se das seguridades e direitos sociais e trabalhistas (NEVES, 2007).

Essa nova era capitalista vivenciada com base no neoliberalismo ocasiona o período denominado por Behring (2008, p. 152) de "contra-reformas do Estado", pois reconfigura todos os aspectos na vida social e das relações sociais, retrocedendo direitos assegurados e implementados por políticas públicas.

Já no plano ídeo-cultural mais amplo, a ofensiva neoliberal contrapõe-se abertamente à cultura democrática e igualitária da época contemporânea, caracterizada não só pela afirmação da igualdade civil e política para todos, mas também pela busca da redução das desigualdades entre os indivíduos no plano econômico e social. (NUNES, 1991, p. 502 apud PAULO NETTO, 2007, p. 78).

A efetivação dos direitos se torna ainda mais difícil, mediante ao contexto de austeridade orçamentária, e "esse Estado mínimo (ou máximo para o capital)" (PAULO NETTO, 2007, p. 81). O Estado de BemEstar Social, assim como o neoliberalismo, fora uma saída capitalista dentro do próprio capitalismo, configurando uma espécie de reforma dentro da própria ordem, que demonstrou em seu exaurimento a incompatibilidade de pensar nos marcos do capitalismo uma real igualdade para todos, com redução de desigualdades e garantia de direitos. Esse dado sinaliza os desafios da classe trabalhadora para o enfrentamento aos rebatimentos e consequências das formulações e readequações do capital, "[...] a crise do Welfare State explicita o fracasso do único ordenamento sócio-político que, na ordem do capital, visou expressamente compatibilizar a dinâmica da acumulação e da valorização capitalista com a garantia de direitos políticos e sociais mínimos". (PAULO NETTO, 2007, p. 68).

Os anos de 1990 até os dias de hoje têm sido de contrarreforma do Estado e de obstaculização e/ou redirecionamento das conquistas de 1988, num contexto em que foram derruídas até mesmo aquelas condições políticas por meio da expansão do desemprego e da violência. (BEHRING; BOSCHETTI, 2011, p. 147).

Como abordado anteriormente, na particularidade brasileira, a política social, de corte neoliberal foi implementada com o objetivo de adequação às novas necessidades da política macroeconômica internacional. Cabe ressaltar que o Brasil, por ser um País periférico e que não teve um Estado de Bem-Estar Social, apresenta uma concepção reducionista na construção dos direitos, nos mecanismos compensatórios que se implementaram (como a política de combate à pobreza). Isso vai fazendo com que os próprios trabalhadores se adequem ao discurso esvaziado de direitos, que legitima a perspectiva neoliberal e desarticula a fundamentação dos direitos baseados na construção sócio-histórica das lutas de classes, naturalizando-os e acreditando por ter um aparato legal que esses direitos sejam realmente implementados.

O cenário contemporâneo, que circunscreve as políticas sociais, revela uma série de reformas, ou melhor dizendo, "contra-reformas" como afirma Behring (2008, p. 150). Para trilhar esse caminho, é importante levar em conta a conjuntura que perpassa o tratamento das políticas sociais em sua gênese a fim de desaguar sua gestão na atualidade, entendendo que as políticas sociais expressam um direito social, esse último compreendido enquanto pilar central na busca de equidade e igualdade de acesso a todos. Levando em consideração, também, o papel que tem o Estado, os movimentos sociais e a pressão da classe trabalhadora, para fomentar a criação das políticas.

Houve sim uma mudança profunda na perspectiva do Estado, que abrandou seus princípios liberais e incorporou orientações social-democratas num novo contexto socioeconômico e da luta de classes, assu- 
mindo um caráter mais social com investimento em políticas sociais (PISÓN, 1998). Não se trata, então, de estabelecer uma linha evolutiva linear entre Estado liberal e o Estado Social, mas sim chamar atenção para o fato de que ambos têm algo em comum: o reconhecimento de direitos sem colocar em xeque os fundamentos do capitalismo. (BEHRING; BOSCHETTI, 2011, p. 63).

É a partir do séc. XIX que o Estado capitalista passa a tomar as políticas sociais como uma das medidas na esfera social de forma mais ampla. O estágio de austeridade e barbárie que vem se configurando o capitalismo foi se tornando insuportável e como forma de enfrentamento das tensões geradas e fomentadas a partir da tensão capital x trabalho, as políticas sociais tiveram/têm um caráter central para respostas à classe trabalhadora. "Sem ferir de morte os dispositivos exploradores do regime do capital, toda luta contra as suas ações sócio-políticas (precisamente o que se designa por "questão social") está condenada a enfrentar sintomas, consequências e efeitos”. (PAULO NETTO, 2010, p. 8).

Se as políticas sociais podem ser interpretadas como formas de regulação social, elas não são criadas sem a dimensão da coerção e consenso. Sobre o consenso, adiciono ainda, duas teses de Neves (2007, p. 1) que consiste em analisar a política pública como "[...] instrumento fundamental para difusão de uma nova pedagogia do capital" e que tem como "[...] objetivo consolidar entre nós um novo padrão de sociabilidade, por meio da disseminação da ideologia de responsabilidade social".

Essas medidas foram implementadas a partir da década de 1990 no Brasil sob o contexto de neoliberalismo, que teve três eixos fundamentais para além dos preceitos que eram determinados no seu receituário (CHOSSUDOVSKY, 1999): a intervenção do Estado, mercado como gestor da vida social e o estímulo ao individualismo.

É no governo Fernando Henrique Cardoso (FHC), por meio do Ministério da Administração Federal e Reforma do Estado (MARE), que ocorreram as grandes contrarreformas do Estado. O Ministério camufla a política neoliberal, alegando não defender aos ditames neoliberais e denominando como uma política social liberal, sob o período chamado novo desenvolvimentismo.

Com o objetivo de implementar as contrarreformas.

Não apenas se cruzam as

transações e negociações

financeiras como também a

cultura mundial para

homogeneização da população

para uma mesma demanda,

seja com os bens materiais ou

como o modo de pensar e agir,

ao cabo que facilita a

perpetuação da hegemonia

capitalista. o governo alegou que a constituição de 1988 era atrasada, o Estado ineficiente, transferiu o trato da pobreza, enquanto uma das expressões da questão social, para a sociedade civil e para esfera privada no chamado "terceiro setor" (MONTAÑO, 2010, p. 247). Essa proposta e jogatina política foi mais uma forma que o Estado brasileiro se posicionou para ausentar-se da responsabilidade de implementação de políticas públicas de qualidade na esfera social (NEVES, 2007).

A partir desse momento, o Estado interventor, em âmbito econômico, deu subsídio aos mercados, mas na esfera social difundia a ideia de ineficiência. A desresponsabilização estatal e direcionamento das políticas e serviços sociais para a esfera privada acirrava o quadro de desmantelamento e contrarreformas nos direitos, trazendo profundos retrocessos à classe trabalhadora.

Somado a esse quadro, o Banco Mundial, formula uma nova concepção para a categoria pobreza que recai como uma luva para os direcionamentos do Estado burguês de direito. A pobreza num primeiro momento passou a ser analisada como uma incapacidade do indivíduo em atingir padrões mínimos de vida, enquanto no segundo relatório foi reformulada como "ausências de capacidades humanas"

(UGÁ, 2004, p. 59), cabendo ao Estado, portanto, gerar o ponta pé inicial para essas capacidades serem desenvolvidas e ao indivíduo, de forma focalizada, cabe empoderar-se ${ }^{4}$ (UGÁ, 2004).

Esse quadro fomentou a privatização dos serviços públicos e a refilantropização da questão social, fomentando um processo de assistencialização da proteção social, que tem como pilar central desse pensamento a política de assistência social. Como aconteceu no governo Lula e no governo Dilma. Políticas como Quem tem fome, tem pressa, Fome zero e Bolsa-família são formas de uma política assistencialista e minimalista, que (ainda que atendendo minimante e de forma imediata os usuários que delas se utilizam) utiliza-se da legitimação da atual configuração voltada para alívio da miséria, já que em sua essência, é centrada em conter 
gastos sociais necessários para direcionar mais verba ao pagamento da dívida pública de novas possibilidades de mercado (CHOSSUDOVSKY, 1999).

Contemporaneamente as concepções para formulação das políticas sociais têm em seu cerne: a vulnerabilidade, pobreza, empregabilidade, empreendedorismo, capacidades humanas e empowerment ${ }^{5}$. Além de servir enquanto disseminação da ideologia de responsabilização social, sobre um Estado que não tem possibilidade de arcar tudo sozinho, mas um Estado que necessita de parcerias (intensificando as parcerias público-privadas) e perpassando a "nova pedagogia de hegemonia do capital". (NEVES, 2007, p. 1).

Assim a tendência geral tem sido a de restrição e redução de direitos, sob argumento da crise fiscal do Estado, transformando as políticas sociais - a depender da correlação de forças entre as classes sociais e segmentos de classe e do grau de consolidação da democracia e da política social nos países - em ações pontuais e compensatórias direcionadas para os efeitos mais perversos da crise. (BEHRING; BOSCHETTI, 2011, p. 156).

Contudo, fica evidenciado que a ofensiva neoliberal implementada na particularidade sócio-histórica da sociedade brasileira a partir da década de 1990 abarcou: reestruturação produtiva, contrarreforma do Estado, financeirização do capital com todo contexto de refilantropização da questão social, desresponsabilidade estatal com transferência para o "terceiro setor" (MONTAÑO, 2010, p. 247) ${ }^{6}$, incentivo ao voluntariado/caridade e privatizações (além das parcerias público-privadas), o que acabaram por esvaziar a noção de direitos.

As características esparsas e falhas das medidas de proteção social no Brasil que citam as autoras Behring e Boschetti (2011) estão interligadas também ao movimento de reivindicação de classe e as lutas que travam de acordo com a conjuntura que ao logo do tempo se configura. A construção dos direitos sociais se deu em um contexto atrasado se comparado aos países centrais, visto, logicamente, a formação sócio-histórica que acometeu o Brasil e traz repercussões até os dias atuais.

Se a política social tem relação com a luta de classes, e considerando que o trabalho no Brasil, apesar de importantes momentos de radicalização, esteve atravessado pelo escravismo, pela informalidade, pela fragmentação/cooptação, e que as classes dominantes nunca tiveram compromissos democráticos e redistributivos, tem-se um cenário complexo para as lutas em defesa dos direitos de cidadania, que envolvem a constituição da política social. É nesse quadro que se devem observar as medidas esparsas e frágeis de proteção social no país até a década de 1930, embora tais características sejam persistentes e nos ajude também a pensar os dias de hoje. (BEHRING; BOSCHETTI, 2011, p. 79)

\section{Considerações finais}

Considerando as reflexões já realizadas nesse trabalho, ressalto, portanto, que as marcas de "modernização conservadora" (COUTINHO, 1989, p. 38), "cidadania regulada" (SANTOS, 1987 apud CARVALHO, 2011, p. 115)7, "revolução pelo alto" (IANNI, 1981, p. 11) e assistencialismo parecem inerentes à constituição sócio-histórica brasileira que teve e tem pela intervenção estatal, o binômio de coerção x consenso muito arraigado na história brasileira. O que se conquista por direito é transfigurado em benefício e todo avanço que se dá, se faz de modo articulado, restrito, seletivo e meritocrático, evidenciando a intervenção Estatal por meio das políticas sociais e econômicas.

Em suma - mas não findando o debate - os direitos que são expressões da luta de classes através de muitos embates passam a ser naturalizados e tidos como benefícios. Esses direitos assegurados em âmbito legal, no real, passam a sofrer desmontes e cerceamento pela esfera privada, camuflando a sociedade classista inerente ao sistema capitalista e usa do discurso de cidadania para igualar a população política e civicamente, reconhecendo as pessoas enquanto cidadãos e não enquanto trabalhadores. Defendem o direito à liberdade e propriedade privada em detrimento aos direitos sociais.

Todavia, os direitos sociais proclamados nos estatutos legais nem sempre são passíveis de serem efetivados, visto que dependem de vontade política e de decisões governamentais. Com Nogueira (2001), poderse-ia afirmar que são "direitos que carecem desesperadamente de proteção política e cultura cívica. Para serem efetivamente usufruídos, requerem mudanças nos termos da convivência social", dentro de uma estratégia radicalmente democrática. (IAMAMOTO, 2000, p. 263).

A grandiosidade das decisões governamentais e legais, a forma que culturalmente o Brasil, de modo peculiar, tem arraigado a concepção do que é direito e a intensificação da forma como a pobreza foi criminalizada 
e teve um novo significado, principalmente partir da década de 1990 com o avanço neoliberal. E a essa cultura cívica, ainda sob avanços e retrocessos, necessita de muito mais debates críticos sobre o tema, a fim de desmistificar o que, no Brasil, devido a uma série de particularidades históricas, dificultaram a compreensão da raiz do subdesenvolvimento, de inerentes crises cíclicas, da configuração e significado de direito e do fundamento gerador que se aprofunda a desigualdade no País.

Nem mesmo a abolição da escravidão e a promulgação da Constituição Federal de 1988 romperam com a formação cultural e socioeconômica que havia no País. Os ideais difundidos pela hegemonia conservadora do capital contemporâneo ainda são utilizados como estratégia de controle social, como agente indispensável para tomadas de posição astuciosas nos campos políticos, econômico e social com caráter autoritário, intolerante e excludente.

Por esses e outros motivos, é imprescindível a articulação e luta política em defesa dos direitos sociais, civis e políticos no contexto contemporâneo, afinal mesmo com toda trajetória de luta para efetivação da cidadania e dos direitos já adquiridos e previstos em lei, os ataques capitalistas continuam a acontecer em uma tentativa de apenas regredir e retroceder, não pretendendo sanar nem mesmo as necessidades sociais básicas.

\section{Referências}

BEHRING, E. R. Brasil em contra-reforma: desestruturação do Estado e perda de direitos. 2. ed. São Paulo, Cortez, 2008.

BEHRING, E. R; BOSCHETTI, I. Política Social: fundamentos e história. São Paulo: Cortez, 2011.

BRASIL. [Constituição (1988)]. Constituição da República Federativa do Brasil de 1988. Brasília, DF: Presidência da República, [2018]. Disponível em: http://www.planalto.gov.br/ccivil_03/Constituicao/ConstituicaoCompilado.htm. Acesso em: 28 dez. 2018.

CARVALHO, J. M. de. Cidadania no Brasil: o longo caminho. 14 ed. Rio de Janeiro: Civilização Brasileira, 2011.

CHESNAIS, F. A mundialização do capital. São Paulo: Xamã, 1996.

CHOSSUDOVSKY, M. A globalização da pobreza: impactos das reformas do FMI e do Banco Mundial. São Paulo: Moderna, 1999. COUTINHO, C. N. Gramsci: um estudo sobre seu pensamento político. Rio de Janeiro: Campus, 1989.

DIAS, E. F. A liberdade (im)possivel na ordem do capital, reestruturação produtiva e passivização. 2. ed. rev. e ampliada. Campinas: IFHC/Unicamp, set. 1999. (Textos didáticos, n. 29).

FERNANDES, F. A revolução burguesa no Brasil: ensaio de interpretação sociológica. Rio de Janeiro: Zahar, 1976.

HAYEK, F. A. O caminho da servidão. Rio de Janeiro: Instituto Liberal, 1990.

IAMAMOTO, M. V. O Serviço Social na contemporaneidade: trabalho e formação profissional. São Paulo: Cortez, 2000.

IAMAMOTO, M. V. Serviço Social em tempo de capital fetiche. 3. ed. São Paulo: Cortez, 2011.

IANNI, O. A ditadura do grande capital. Rio de Janeiro: Civilização Brasileira, 1981.

LIMA, R. S. Orçamento público dos abrigos municipais no Rio de Janeiro: velhos e novos dilemas. 2013. Tese (Doutorado em Serviço Social) - Programa de Pós-Graduação em Serviço Social, Universidade do Estado do Rio de Janeiro, Rio de Janeiro, 2013.

MARX, K. O capital: crítica da economia política. 3. ed. São Paulo: Nova Cultura, 1988.

MAZZEO, A. C. Estado e burguesia no Brasil: origens da autocracia burguesa. São Paulo: Cortez, 1997.

MONTAÑO, C. Terceiro setor e questão social: crítica ao padrão emergente de intervenção. São Paulo: Cortez, 2010.

NEVES, L. M. W. Políticas sociais contemporâneas: teses para discussão. In: CONGRESSO NACIONAL DE ASSISTENTES SOCIAIS POLÍTICAS PÚBLICAS \& SERVIÇO SOCIAL: análises e debates, 12., 2007, Foz do Iguaçu. Comunicação [...]. Foz do Iguaçu: Observatório Social, 2007. p. 1-13.

PAUlO NETTO, J. Crise do socialismo e ofensiva neoliberal. 4. ed. São Paulo: Cortez, 2007.

PAULO NETTO, J. Introdução ao estudo do método de Marx. São Paulo: Expressão Popular, 2011.

PAULO NETTO, J. Uma Face Contemporânea da Barbárie. In: ENCONTRO INTERNACIONAL "CIVILIZAÇÃO OU BARBÁRIE", 3., 2010, São Paulo. Comunicação [...]. São Paulo: Serpa. 2010. p. 1-32.

SANTOS, W. G. dos. Cidadania e justiça: a política social na ordem brasileira. 2. ed. rev. e atual. Rio de Janeiro: Campus, 1987.

UGÁ, V. D. A categoria “pobreza” nas formulações de política social do Banco Mundial. Revista de Sociologia e Política, Curitiba, n. 23, p. 55-62, nov. 2004.

\section{Notas}

1 Principalmente na Europa, onde a revolução burguesa propiciou uma ruptura com estruturas sociais arcaicas introduzindo um novo padrão de desenvolvimento (BEHRING; BOSCHETTI, 2011).

2 O New Deal representou “"...] uma saída pragmática empreendida por Roosevelt nos EUA durante seus dois primeiros mandatos (1932-1936 e 19361940) com vistas a retomada econômica. [...] O New Deal marcou um período de forte intervenção estatal na regulação da política agrícola, industrial, monetária e social, demarcando um recuo em relação ao liberalismo predominante até então". (BEHRING; BOSCHETTI, 2011, p. 71). 
3 Os ideais do neoliberalismo já estavam estruturados a partir do debate feito por Friedrich Hayek (1990), no livro publicado desde 1944 e intitulado como $O$ caminho da servidão.

4 Em nenhum momento essa característica vislumbra a uma consciência política e coletiva, muito pelo contrário.

5 "Como a pobreza e a desigualdade social são dissociadas de processos estruturais, a saída se constrói através do investimento e ações de alívio da pobreza via capacitação do indivíduo para a autoproteção." (MAURIEL, 2006, p. 76 apud LIMA, 2013, p. 130, grifo do autor).

6 Ver a relevante crítica ao chamado "terceiro setor" realizada por Montaño (2010, p. 247), que, segundo o autor, instaura uma ausência de ação no cenário social mediante ao processo de desresponsabilização estatal.

7 '“[...] a política social foi bem caracterizada por Wanderley G. dos Santos (1987) como 'cidadania regulada', isto é, uma cidadania limitada por restrições políticas." (CARVALHO, 2011, p. 115).

\section{Lais do Nascimento Vidal Lage}

laisvidall@hotmail.com

Bacharelado em Serviço Social pela Universidade Federal Fluminense (UFF)

Mestranda em Serviço Social na Universidade Federal do Rio de Janeiro (UFRJ)

\section{UFRJ}

Escola de Serviço Social

Av. Pasteur, 250, Fundos - Urca

Rio de Janeiro - Rio de Janeiro - Brasil

CEP: $22.290-240$

\section{Agradecimentos}

Muito das reflexões levantas neste artigo se devem aos constantes debates realizados nas universidades federais de ensino por onde passei, meus agradecimentos aos professores e amigos que fomentaram sempre tantas reflexões. A Deus, toda minha vida. Ao meu esposo, meu filho Heitor, aos familiares e amigos, toda minha gratidão e lealdade. Sem vocês não daria.

\section{Agência financiadora}

Não se aplica.

\section{Contribuições dos autores}

Não se aplica.
Aprovação por Comitê de Ética e consentimento para participação

Não se aplica.

Consentimento para publicação

Não se aplica.

\section{Conflito de interesses}

Não há conflito de interesses. 